\title{
Alegría y temblor (la pintura de Ramón Gaya) ${ }^{1}$
}

\author{
Pedro García Montalvo \\ Escritor
}

A Cuca

«EN FEBRERO HABRÁ UNA EXPOSICIÓN DE GAYA». Una frase así vendría a ser para mí equiparable -si pudiera olvidar el hecho esencial de que se trata de la obra de un pintor, de un creador- a otras frases como: «Hace mucho frío estos días de enero», «Nieva ya en las tierras altas murcianas», o «Los almendros florecerán a principios de mes». Es casi -de no ser por ese hombre que hay detrás-como uno de esos hechos de la presente estación invernal, de los que dan cuenta los almanaques del tiempo o esos calendarios que hablan de los paisajes del campo abierto, y de los húmedos días que impregnan las grandes ciudades ${ }^{1}$.

Así pues, en cierto sentido, ver esta exposición es casi como ver posarse sobre la naturaleza, y sobre la actualidad, un suceso, un fenómeno, o, mejor, un prodigio estacional - gotas de llovizna, cristales de rocío, motas de sol- en un tapial, o en un ribazo. No de otra manera, en estos comienzos de 2007 germinan, abren su ser estas pinturas y dibujos gayescos en las paredes de la sala. Sólo que estos cuadros hablan además de la mano firme del hombre que los ha creado. Estas obras que tienen que ver con lugares amados por el pintor, desde México a Roma, Aix-enProvence, Venecia, París, Murcia y sus huertos, Saint-Rémy... Desde los puestos de los bouquinistas en la sombra gris de los plátanos del Sena a las luces de la mañana en el blanco Palacio Ducal veneciano.

$$
* * *
$$

En pocas manifestaciones de la pintura he visto yo con tanta nitidez como en los cuadros de Ramón Gaya cierta cualidad esencial de las cosas, del mundo, que vale para todas las formas de la creación, pero que se hace muy patente en el hecho de pintar.

\footnotetext{
${ }^{1}$ Texto para el catálogo de la exposición «Ramón Gaya», en el Auditorio de Ceutí, inaugurada el 8 de febrero de 2007.
} 
Recuerdo que en mis años infantiles -o quizás, un poco más tarde, en el inicio de mi adolescencia-, oí yo por primera vez, en el Colegio del Malecón de mi ciudad, o en alguna iglesia de los barrios en los que fui viviendo, la expresión «temor y temblor», en su sentido religioso. En una misa, o en alguna de las nocturnas Misiones que se hacían anualmente por las parroquias, yo escuché por primera vez las palabras «Temor y Temblor», en un sermón o lectura, sin saber a qué fragmento de la Biblia pertenecerían. No sé si esas palabras llegarían a mí, entre la gente, en mi banco de madera, porque leían en el púlpito la II Epístola de San Pablo a los Corintios («viendo vuestra obediencia, y el temor y temblor con que le recibisteis») o la Epístola a los Filipenses («buscad vuestra salvación con temor y temblor»). Tendrían que pasar muchos años antes de que yo las buscara en su texto. En todo caso, en aquella época colegial esas palabras eran para mí como un resumen solemne, oscuro y resonante del misterio de la religión.

Andando el tiempo -sería poco después-, volví a encontrarlas, pero ahora como título de un libro de filosofía, el libro de un pensador inexorable y apasionado: «Temor y temblor». Así se contaba en mi primer manual de Filosofía, el Edelvives, tan aristotélico, tan escolástico. Allí surgió ante mis ojos el nombre de Kierkegaard y de esa obra, aún más severa en su nombre danés, Frygt og Baven.

Hasta que un día pensé que había otro temblor en la vida y en las cosas naturales. Un temblor feliz - que quizás participaba del otro, y que incluso era como otra forma del mismo-, asociado a la más profunda alegría, a una musicalidad pura de la naturaleza, que hubiera dado lugar justamente a otro título: «Alegría y temblor».

Años después consideré ese título para hablar alguna vez de la pintura de Ramón Gaya. Porque en ella se daba esta doble cualidad esencial de lo alegre y lo tembloroso, de la belleza gozosa y el temblor. Vuelvo a sentirlo plenamente estos días, mientras contemplo los cuadros que se van reuniendo para esta muestra, estas obras donde se ha omitido todo dramatismo -pero sin idealizar nada-, dejando el puro goce estremecido de la vida: lo toco con mis ojos en el quieto mecerse de las negras góndolas en la Riva degli Schiavoni, con el Redentore al fondo; en la presencia trémula de los foros romanos de pinos oscuros y tejados y cielos claros, donde vibra la luz en un par de cúpulas azules y grises. Este otro temblor de lo vivo, no menos asociado a la mano divina que lo dejó ir en la libertad agreste del mundo, destella en todos los cuadros que voy viendo: en el puente de la estrecha calleja veneciana - de casas muy altas- que duda entre las luces y las sombras; en el dorado tremolar de la luz del sol en una huerta murciana en la que vemos la sombra del pintor -con sombrero-y de su lienzo, junto a una senda con árboles y ramas de un verde claro...

La vida es un acto: está ahí, actual, presente. Pero a menudo sentimos que encierra en sí algo que puede llevarla más allá de sí misma. Que es ya, al tiempo de mirarla, 
algo más que sí misma. Es a la vez pura potencia a punto de ejercerse. Por eso sentimos ese temblor íntimo. Entre la potencia y el acto -hablando en abstractoparece que no hay fluidez, continuidad, que se da un salto. Pero no es así en la vida. Ese temblor de lo vivo implica el puente invisible entre la potencia y el acto.

$$
* * *
$$

En la creación artística ese temblor está también como algo esencial. Aunque a veces -¿cómo decirlo? -, no tiembla, no se manifiesta. Pero está siempre ahí.

Es el temblor de los poemas japoneses, de los versos de Machado cuando nos dice: «Treme el campo en sueños», o cuando canta: «Los chopos son la ribera, en su eterno escalofrío» (un escalofrío gozoso, cálido, que no es más que su propia hondura). O el de un verso del propio Gaya que habla de la mano del artista, una mano «intensa, temblorosa». Como el dulce temblar de quien está enamorado al pensar en quien ama. Y que dice después a su amor: «Tiemblo al pensar en ti».

Como Dante cuenta que Paolo besa a Francesca, haciendo que ella misma nos diga: «La bocca mi baciò tutto tremante».

Pasar ante los cuadros de Ramón Gaya, en su Museo, en esta exposición, esos cuadros tan ricos en matices, de una belleza tan abierta, tan palpitante, es como pasar a lo largo de un bosque de ribera, frondoso y delicado -esa obra maestra del temblor-, reflejado en la orilla del agua de un río, y contemplar la cambiante luz del tapiz silvestre y húmedo de sauces, mimbreras, alisos, espinos amarillos, chopos tempranos y salgueras, en los que se enredan los destellos del sol, y que, incluso estando quietos, tienen siempre algo tembloroso en su imagen: la inminencia de la brisa que los avivará. Un roce de aire que es, en realidad, una brisa interior, suya, de ellos, de su propio y secreto ser. Y que no viene de fuera. Como le ocurre a todo lo vivo.

Ésa es la impresión que los cuadros de Gaya, en la rica belleza de su luz, de su color, nos producen, cuando pasamos despacio, con largas paradas, ante su ser: como si ellos estuvieran también asomados en una viva orilla en la que han nacido. Y tuvieran no sólo su luz propia, sino también ese su temblor propio.

A esta exposición la recorre, por lo demás, otro estremecimiento. A veces muy cercano; a veces, lejano -como el titilar de las estrellas en el cielo de la madrugada-; un estremecimiento en el que pensamos quizás en el momento de contemplar alguno de estos cuadros. Desde hace más de un año, su pintor ya no está entre nosotros para verlos. Aunque en cierto modo lo sentimos muy próximo -quizás más que nunca-, mirando, siempre, hombro con hombro, a nuestro lado. 
Pero el estar de un creador, incluso en vida, cuando ya ha hecho su creación, es siempre una ausencia. Es como en la anécdota del pintor que no tenía invitación para entrar al ámbito de su propia sala. Ahora Ramón Gaya ha cumplido con esa última tarea del artista, en un sentido, dura y difícil, pero también la más pura y honda: dejar sola y libre a su obra.

Como libres fluyen el verso, el agua, y la ribera del río. 